\title{
Retrospective Study of Prosthetic Augmentation Mammoplasty in Transwomen
}

\author{
T. M. Balakrishnan ${ }^{1, \odot ~ S a n d e e p ~ N a g a r a j a n ~}{ }^{1} \quad$ J. Jaganmohan ${ }^{1}$ \\ ${ }^{1}$ Department of Plastic and Faciomaxillary Surgery, Madras Medical \\ Address for correspondence T.M. Balakrishnan, MBBS, MS (Gen Surg), \\ College, Chennai, Tamil Nadu, India \\ FRCS (E), DNB (Gen Surg), MCh (Plastic Surg), DNB (Plastic Surg), Old no 15 \\ New no 10, Thiruvalluvar street, Rangarajapuram, Kodambakkam, Chennai, \\ Tamil Nadu 600024, India (e-mail: thalaiviri.b@gmail.com).
}

Indian J Plast Surg 2020;53:42-50

\begin{abstract}
Introduction Hormonal therapy and gender-conforming surgeries are the treatments of choice in appropriately selected male-to-female transsexuals. The Prosthetic Augmentation Mammoplasty (PAM) in transwomen is the second most common sex conforming procedure performed in our department.

Aim This study was aimed to assess the esthetic outcomes of PAM performed from 2007 to 2017 in 42 transwomen.

Patients and Methods It is a retrospective study wherein the documents of 42 transwomen who had undergone PAM were reviewed. Twenty-three transwomen who had pinch fold thickness more than $2.5 \mathrm{~cm}$ had undergone subglandular/subfascial (SG/SF) plane augmentation; rest had dual plane augmentation. All the cases were followed-up for an average period of 45 months. A validated institutional score for

Keywords

- prosthetic augmentation mammoplasty

- male to female transsexuals

- transwomen

- hormonal mammogenesis

- feminizing male chest

- gender dysphoria subjective assessment and objective assessment (by two independent observers) were used at the end of follow-up period.

Statistical Analysis Used Student's t-test was used for statistical analysis.

Results On an average, $92.85 \%$ of transwomen achieved grade-A score with both subjective and objective assessment scoring system.

Conclusion PAM gives a finishing and colossal touch for transwomen to orient their somatic sex to psychic sex. To get the best cosmetic outcomes and lasting results the PAM in transwomen has to be made a more reasoning and scientific procedure rather than an emotional and irrational procedure. Author's PAM approach facilitates transwomen to rejoice their veritable total genderness in harmony with their gender identity.
\end{abstract}

\section{Introduction}

Transsexual patients commonly perceive breasts as a strong image of the feminine gender and often seek feminization through breast augmentation. Hormonal therapy and gender-conforming surgeries are the treatment of choice in appropriately selected male-to-female transsexuals. However hormonal therapy alone is often insufficient to produce adequate breast development. Prosthetic Augmentation Mammoplasty (PAM) in the transwomen consummates the complete feminity feeling in them. Hence, majority of them eventually seek PAM to establish their complete feminine identity. Hypomastia generates negative body image in all transwomen, which has many repercussions in their social intermingling, and self-esteem. PAM fillips their self-esteem and boosts their feminine feeling. However PAM should not be undertaken before maximum achievable breast enlargement with hormonal therapy. The PAM in transwomen is the second most common sex conforming procedure performed in our department.

\section{Aim}

This study was aimed to evaluate the esthetic outcomes of PAM and its impacts on the psychosocial well-being of transwomen.
License terms

() (1) $\Theta \circledast$ 


\section{Patients and Methods}

The documents of 42 male-to-female transsexuals who underwent PAM from 2007 to 2017 were reviewed in this retrospective study. The first author operated all cases. Institutional ethical committee approval was obtained for this study.

\section{Selection Criteria}

1. Author's criteria for the candidacy of PAM were based on the version seven of "The World Professional Association for Transgender Health Standards of Care." ${ }^{1}$ However, a minimum of 2 years of continuous hormonal therapy before proceeding to PAM was the author's modified preferred criteria.

2. All the transwomen should have undergone bottom (genitalia alteration) surgery.

\section{Exclusion Criteria}

- Those transwomen who had autologous fat augmentation of breast.

- Those transwomen with retroviral positive status with CD4 count less than 400 cells per cubic millimeter.

- Those transwomen who had psychiatric problems.

- Those transwomen who continued nicotine and other drugs abuse.

- Those transwomen with Diabetes, Systemic hypertension, Vasculitis and other co-morbid illnesses.

\section{Preoperative Evaluation}

It was essential to understand the motivation, expectation, and desires of the patients. A thorough evaluation by psychologists and psychiatrists' team were done routinely in all cases to rule out any deep-seated mental disturbances and psychiatric problems in transwomen population opting for PAM. In fact minimum of three consultations were made as mandatory by the author to ensure the transwomen is stable minded and has realistic expectation. As most of the transwomen who opted for PAM in the author's study were retroviral positive, their candidacy for the PAM was considered only if CD4 cell count was more than 400 cells per cubic millimeters. This correlated with their regaining wound healing potential and immunity. ${ }^{2}$ Routine preoperative mammography was done in all the cases. Informed consent for the surgery and use of the photographs for research, publication, and teaching purposes were obtained from each patient.

Complete physical examination of the breast and axilla were performed. Presence of any asymmetry in the position and dimension of nipple areola complex (NAC), breast, inframammary fold (IMF), and axillary tail were noted and conveyed to the patient. There is no quick fix and easy way for the selection of breast implant shape, size, and volume. The arduous step in the PAM is the selection of characteristics of implant based on the chest and body morphology. Author followed a systematic approach in arriving at the decision regarding the implant characteristics in each case. Their body habitus, body mass index (BMI), chest shape, present bra size, breast glandular margin beyond the areolar border, sternal notch to nipple (SNN) distance, nipple to inframammary fold distance (NIMF), breast base distance (BBD; between anterior axillary fold line and parasternal border at the fourth rib level), internipple distance (IND), anteroposterior stretch and pinch thickness in the upper pole and inferior fold were noted. In the hypersthenic transwomen if the SNN distance was more than $21 \mathrm{~cm}$, then the anatomical cohesive silicone gel implants (ACGI) were used and if it was less than $21 \mathrm{~cm}$ round implants were used. The breast implant base diameter (BIBD) was chosen in such a way that it was usually the same or $1 \mathrm{~cm}$ less than BBD. If the chest wall was wide and barrel shaped, BIBD was same as BBD. Based on the anteroposterior stretch, amount of breast tissue and BBD, volume of the implant was determined (with tempered thoughts not to overstretch the breast envelope and precipitate atrophy, visibility, palpability, and reoperation). Implant pocket was decided based on the amount of breast tissue available, chest shape, chest width, and pinch thickness. If the chest was narrow with small breasts and if the pinch thickness was less than $2 \mathrm{~cm}$, the author chose the dual plane, subglandular/submuscular (SG/SM) plane. For those with wide chest, moderate breast and with pinch thickness more than $2 \mathrm{~cm}$, the SG/SF pocket was chosen. Author's preferred choice was textured silicone implants only as they are capable of reducing capsular contractures with good implant stability. The author's choice was always IMF access incision as this facilitated a crisp IMF design. It was usually of $4.5 \mathrm{~cm}$ in length; placed in such a way that three-fourths of it lied lateral to the breast meridian.

\section{Surgical Technique}

Markings were done preoperatively on the day of surgery, with patient standing and arms by the side. The midline was marked first from Suprasternal notch to xiphisternum (XS). The boundary of the existing breast tissue was marked ( - Figs. 1 and $\mathbf{2}$ ). Keeping this boundary as the reference, the proposed boundary of augmented breast was then marked all around centering the existing NAC, corresponding to the base diameter of the chosen implant. The IMF incision line was marked $0.5 \mathrm{~cm}$ below this boundary. To ensure symmetrical outcome, the following three dimensions must be equal on either side:

\section{SNN dimension (-Fig. 2).}

2. The distance between suprasternal notch and the upper pole of the proposed augmented breast markings.

3. The distance between NAC and IMF. The marking of the breast pocket was made centered around the existing NAC and within the marked chest wall BBD. 


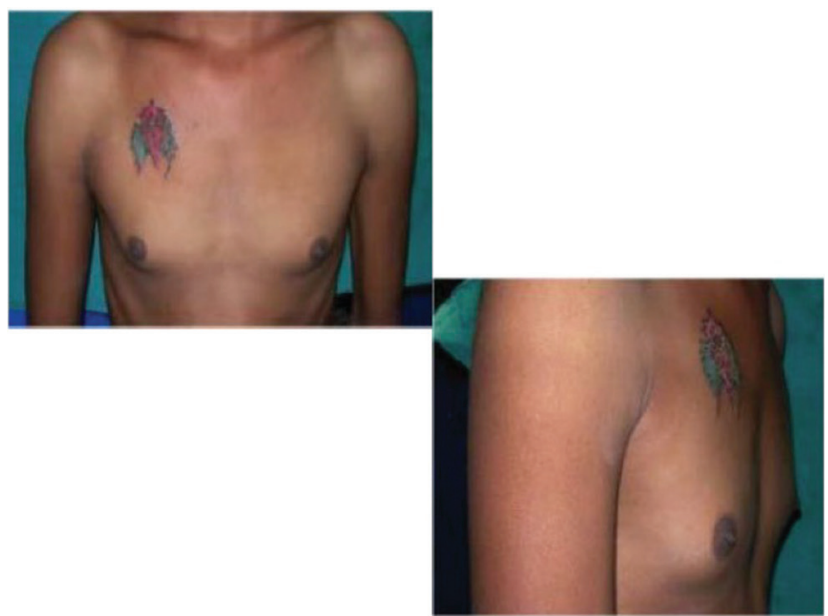

Fig. 1 Case 1 preoperative frontal and profile view.

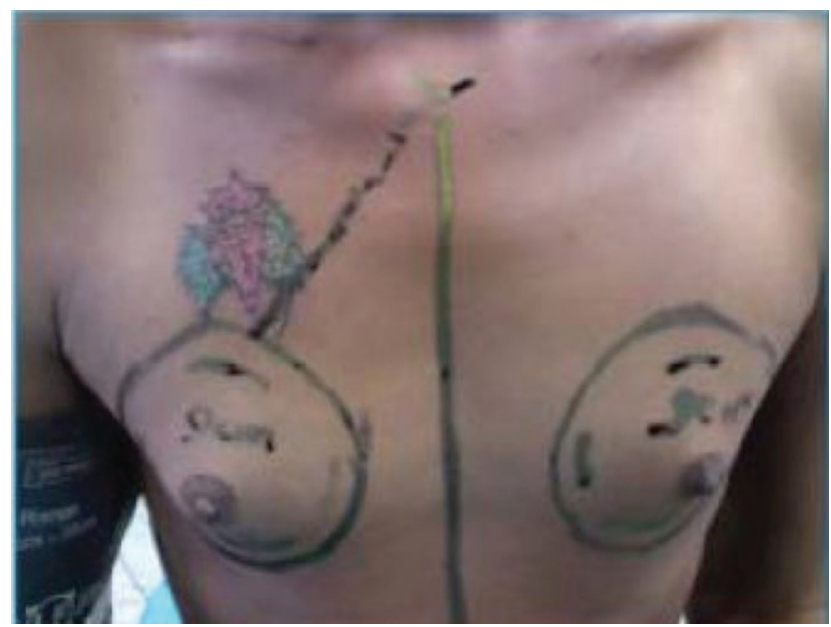

Fig. 2 Case 1 preoperative markings.

\section{Surgical Technique for Subglandular/Subfascial Implantation}

Patient was positioned supine under general anesthesia, and after tumescent infiltration, incision was placed as described previously. Dissection was performed in a plane between the pectoral fascia (continuation of Scarpa's fascia) and the muscle (pectoralis major and serratus anterior). A pocket was created in the SG/SF plane that was slightly more than the required size. Hemostasis was achieved under direct vision. Then the implants were placed on both the sides. Trial stitches were made and patient was then changed to semirecumbent posture to check the shape, symmetry, level of NAC and the position of the newly formed IMF. Once everything was confirmed, patient's position was again changed to supine and the incision line was closed in three layers using monofilament absorbable sutures without any drain.

\section{Surgical Technique for Subpectoral/Subfascial Dual Plane Implantation}

Here the dissection was performed from the IMF line deep to the pectoral muscle after careful identification of its inferolateral border. Adequate pocket was created with careful maintenance of anterior cutaneous branches of the intercostal nerves. The dual plane pocket was created by releasing the inferior medial pectoralis major muscle fibers anterior to the sixth costal cartilage where they interdigitate with the external oblique uppermost fibers, without violating sternal attachment. This step prevents the "window shade" and "piston deformities." In addition no subfascial dissection was performed along the inferolateral border of the pectoralis major as this would result in "double bubble deformity." Then similar steps of the securing hemostasis and implant insertion were followed and position checked. Then layered closure without drain was given.

\section{Postoperative Care}

Dressing was done with preoperatively selected autoclaved padded brassiere.

Postoperatively bathing was allowed after 48 hours. Patients were usually discharged after 3 days. Broadspectrum antibiotic and analgesics were given for 1-week post operatively. Trimming of subcuticular stitches were done on the 10th postoperative day.

\section{Postoperative Follow-up}

Patients were reviewed at 6th, 12th, 18th, 24th, 36th, and 48th months postoperatively. Postoperative photographs were obtained in standard views at all contact time. The surgical team collected and documented the data on "Institutional Score System For Augmentation Mammoplasty-Subjective" (ISSAM-S; - Tables $\mathbf{1}$ and $\mathbf{2}$ ) from each patient at every visit as a subjective assessment. At 24 months, two independent observers also assessed the objective outcomes (Institutional Score System For Augmentation Mammoplasty-Objective" (ISSAM-0; - Table 3). Final scores were computed and analyzed for each patient. The maximum score in ISSAM-O is 16 and minimum being 6 (-Table 3 ). The maximum score in ISSAM-S is 35 and minimum being 7 (-Table 2 ).

\section{Case 1 Illustration}

A 28-year-old transwoman was presented 2 years after the bottom surgery for PAM. She had $2.5 \mathrm{~cm}$ of palpable breast tissue felt beyond the areolar border ( $\boldsymbol{- F i g s .} \mathbf{1}$ and $\mathbf{2}$ ) after 3 years of antiandrogenic hormonal therapy. After preoperative workup and consultations, she had undergone PAM with $280 \mathrm{~mL}$ round implant, low profile inserted in dual plane pocket. ISSAM-O and $-\mathrm{S}$ computed final grades at the end of 18 months of follow-up were grade A ( - Fig. 3 ).

\section{Case 3 Illustrations}

A 26-year-old transwoman had undergone PAM with 200 $\mathrm{mL}$ ACGI, high-profile implant inserted into SG/SF plane. Preoperatively, she had 3.5 years of hormonal therapy with well-developed breast tissue ( $\boldsymbol{- \text { Fig. }}$ 4). With sthenic body habitus, she had an SNN distance of $23.5 \mathrm{~cm}$. The upper pole pinch thickness was more than $2.5 \mathrm{~cm}$. ISSAM-O and $-\mathrm{S}$ 
Table 1 Demographic details of 42 transwomen who had undergone PAM

\begin{tabular}{|c|c|c|c|c|c|c|c|c|c|c|c|c|}
\hline No. & $\begin{array}{l}\text { Age } \\
(y)\end{array}$ & $\begin{array}{l}\text { Retroviral } \\
\text { status }\end{array}$ & $\begin{array}{l}\text { Shape of } \\
\text { implant }\end{array}$ & BBD & BIBD & $\begin{array}{l}\text { Volume } \\
\text { of } \\
\text { implant }\end{array}$ & $\begin{array}{l}\text { Profile } \\
\text { of } \\
\text { implant }\end{array}$ & $\begin{array}{l}\text { Implant } \\
\text { pocket }\end{array}$ & Complications & $\begin{array}{l}\text { Follow-up } \\
\text { (mo) }\end{array}$ & ISSAM-S & ISSAM-0 \\
\hline 1 & 28 & + & $\mathrm{RI}$ & 11.6 & 10.6 & 280 & LP & DP & & 18 & $A$ & $A$ \\
\hline 2 & 24 & + & $\mathrm{RI}$ & 11.4 & 10.4 & 230 & MP & SG/SF & & 28 & $A$ & $A$ \\
\hline 3 & 26 & + & ACGI & 10.7 & 9.7 & 200 & $\mathrm{HP}$ & SG/SF & & 24 & $A$ & A \\
\hline 4 & 32 & - & $\mathrm{RI}$ & 10.4 & 9.4 & 160 & $\mathrm{HP}$ & SG/SF & & 36 & $A$ & $A$ \\
\hline 5 & 40 & + & $\mathrm{RI}$ & 11 & 10 & 230 & MP & SG/SF & & 26 & $A$ & $A$ \\
\hline 6 & 36 & + & $\mathrm{RI}$ & 11.4 & 10.4 & 260 & MP & DP & & 32 & $A$ & $A$ \\
\hline 7 & 37 & + & $\mathrm{RI}$ & 11.6 & 10.6 & 280 & LP & DP & Migration & 18 & B & B \\
\hline 8 & 34 & + & RI & 10.7 & 9.7 & 200 & $\mathrm{HP}$ & DP & & 20 & $A$ & $A$ \\
\hline 9 & 26 & + & $\mathrm{RI}$ & 11 & 10 & 230 & MP & SG/SF & & 22 & A & $A$ \\
\hline 10 & 32 & + & $\mathrm{RI}$ & 11.6 & 10.6 & 280 & LP & SG/SF & & 24 & $A$ & $A$ \\
\hline 11 & 36 & + & $\mathrm{RI}$ & 10.6 & 9.6 & 180 & $\mathrm{HP}$ & SG/SF & & 32 & A & A \\
\hline 12 & 39 & - & $\mathrm{RI}$ & 11.4 & 10.4 & 260 & MP & DP & Piston effect & 28 & C & C \\
\hline 13 & 32 & + & $\mathrm{RI}$ & 11.6 & 10.6 & 280 & MP & SG/SF & & 28 & $A$ & A \\
\hline 14 & 36 & + & $\mathrm{RI}$ & 10 & 9 & 120 & $\mathrm{HP}$ & DP & & 18 & $A$ & $A$ \\
\hline 15 & 37 & + & $\mathrm{RI}$ & 11.5 & 10.4 & 260 & MP & SG/SF & & 22 & $A$ & $A$ \\
\hline 16 & 35 & + & $\mathrm{RI}$ & 10.6 & 9.6 & 180 & $\mathrm{HP}$ & DP & & 32 & $A$ & $A$ \\
\hline 17 & 26 & + & $\mathrm{RI}$ & 11.6 & 10.6 & 280 & $\mathrm{LP}$ & SG/SF & & 24 & A & $A$ \\
\hline 18 & 29 & + & RI & 11.4 & 10.4 & 260 & MP & SG/SF & & 24 & $A$ & $A$ \\
\hline 19 & 30 & + & ACGI & 11.6 & 10.6 & 280 & $L P$ & DP & & 24 & A & $A$ \\
\hline 20 & 34 & + & $\mathrm{RI}$ & 10 & 9 & 120 & $\mathrm{HP}$ & DP & & 18 & $A$ & $A$ \\
\hline 21 & 36 & + & $\mathrm{RI}$ & 10.7 & 9.7 & 200 & $\mathrm{MP}$ & SG/SF & & 24 & $A$ & $A$ \\
\hline 22 & 34 & + & $\mathrm{RI}$ & 11.6 & 10.6 & 280 & $\mathrm{LP}$ & DP & Migration & 32 & B & B \\
\hline 23 & 33 & + & $\mathrm{RI}$ & 10.7 & 9.7 & 200 & $\mathrm{HP}$ & SG/SF & & 26 & $A$ & $A$ \\
\hline 24 & 34 & + & $\mathrm{RI}$ & 11 & 10 & 230 & $\mathrm{MP}$ & SG/SF & & 24 & $A$ & $A$ \\
\hline 25 & 30 & + & $\mathrm{RI}$ & 11.6 & 10.6 & 280 & LP & DP & & 28 & $A$ & $A$ \\
\hline 26 & 34 & + & $\mathrm{RI}$ & 11.4 & 10.4 & 260 & MP & SG/SF & & 18 & $A$ & $A$ \\
\hline 27 & 36 & + & $\mathrm{RI}$ & 10.1 & 9.1 & 140 & $\mathrm{HP}$ & DP & & 26 & A & $A$ \\
\hline 28 & 34 & + & $\mathrm{RI}$ & 10.4 & 9.4 & 160 & $\mathrm{HP}$ & SG/SF & & 30 & $A$ & $A$ \\
\hline 29 & 35 & + & $\mathrm{RI}$ & 10 & 9 & 120 & $\mathrm{HP}$ & DP & & 28 & A & A \\
\hline 30 & 32 & + & $\mathrm{RI}$ & 11.4 & 10.4 & 260 & MP & SG/SF & & 32 & $A$ & $A$ \\
\hline 31 & 32 & + & $\mathrm{RI}$ & 11.4 & 10.4 & 260 & $\mathrm{MP}$ & SG/SF & & 20 & $A$ & $A$ \\
\hline 32 & 28 & + & $\mathrm{RI}$ & 10.4 & 9.4 & 160 & $\mathrm{HP}$ & DP & & 22 & A & A \\
\hline 33 & 29 & + & $\mathrm{RI}$ & 11.6 & 10.6 & 280 & LP & SG/SF & & 36 & $A$ & $A$ \\
\hline 34 & 28 & + & $\mathrm{RI}$ & 11 & 10 & 230 & $\mathrm{MP}$ & DP & & 24 & $A$ & $A$ \\
\hline 35 & 30 & - & $\mathrm{RI}$ & 11.6 & 10.6 & 280 & MP & DP & & 18 & A & A \\
\hline 36 & 36 & + & $\mathrm{RI}$ & 10.4 & 9.4 & 160 & $\mathrm{HP}$ & SG/SF & & 32 & A & $A$ \\
\hline 37 & 32 & + & $\mathrm{RI}$ & 10 & 9 & 120 & $\mathrm{HP}$ & DP & & 20 & $A$ & $A$ \\
\hline 38 & 34 & + & $\mathrm{RI}$ & 11.6 & 10.6 & 280 & $L P$ & SG/SF & & 20 & A & A \\
\hline 39 & 33 & + & $\mathrm{RI}$ & 9.5 & 10 & 230 & MP & SG/SF & & 22 & A & A \\
\hline
\end{tabular}


Table 1 (continued)

\begin{tabular}{|c|c|c|c|c|c|c|c|c|c|c|c|c|}
\hline No. & $\begin{array}{l}\text { Age } \\
\text { (y) }\end{array}$ & $\begin{array}{l}\text { Retroviral } \\
\text { status }\end{array}$ & $\begin{array}{l}\text { Shape of } \\
\text { implant }\end{array}$ & BBD & BIBD & $\begin{array}{l}\text { Volume } \\
\text { of } \\
\text { implant }\end{array}$ & $\begin{array}{l}\text { Profile } \\
\text { of } \\
\text { implant }\end{array}$ & $\begin{array}{l}\text { Implant } \\
\text { pocket }\end{array}$ & Complications & $\begin{array}{l}\text { Follow-up } \\
\text { (mo) }\end{array}$ & ISSAM-S & ISSAM-0 \\
\hline 40 & 34 & + & RI & 10.7 & 9.7 & 200 & $\mathrm{HP}$ & $\mathrm{DP}$ & & 36 & A & $A$ \\
\hline 41 & 35 & + & RI & 10.1 & 9.1 & 140 & $\mathrm{HP}$ & SG/SF & & 22 & A & $A$ \\
\hline 42 & 32 & - & RI & 11.6 & 10.6 & 280 & LP & $\mathrm{DP}$ & & 18 & A & A \\
\hline
\end{tabular}

Abbreviations: ACGI, anatomical cohesive gel implant; BBD, breast base diameter; BIBD, base implant base diameter; DP, dual plane; HP, high profile; MP, medium profile; LP, low profile; ISSAM-O, institutional score system for augmentation mammoplasty-objective; ISSAM-S, institutional score system for augmentation mammoplasty-subjective; PAM, prosthetic augmentation mammoplasty; RI, round implant; SG/SF, subglandular/subfascial.

Table 2 Institutional subjective satisfaction score for PAM

\begin{tabular}{|c|l|}
\hline No. & \multicolumn{1}{|c|}{ Parameters } \\
\hline 1. & $\begin{array}{l}\text { Postoperative breast dimension, shape and } \\
\text { appearance }\end{array}$ \\
\hline 2. & Feel of breast \\
\hline 3. & $\begin{array}{l}\text { Feel of self-confidence, enhanced beauty and } \\
\text { enhanced body image }\end{array}$ \\
\hline 4. & Sexual attractiveness and sexual satisfaction \\
\hline 5. & Scar pain and thickening \\
\hline 6. & Chest pain \\
\hline 7. & Comfort for physical activity and sleeping \\
\hline Score & \multicolumn{2}{|l|}{} \\
\hline 1-unsatisfactory/discomfort/not satisfactory/felt bad \\
\hline 2-feels good/satisfied/comfortable \\
\hline 3-very good \\
\hline 4-excellent \\
\hline 5-highly satisfied/reinforced/rejuvenated \\
\hline Minimum = 7, maximum = 35 \\
\hline Computation of grades & S-15 \\
\hline Grades & C-35 \\
\hline C & \\
\hline B & \\
\hline
\end{tabular}

Abbreviation: PAM, prosthetic augmentation mammoplasty.

computed final grades at the end of 24 months of follow-up were grade A ( - Fig. $\mathbf{5}$ ).

\section{Statistical Analytical Method Followed in the Study}

Data were entered into Microsoft excel data sheet and was analyzed using SPSS 22 version (IBM SPSS Statistics, Somers, New York, New York, United States) software. Categorical data was represented in the form of Frequencies and proportions. Chi-square test was used as test of significance for qualitative data. Continuous data were represented as mean and standard deviation (SD). Independent $t$-test was used as test of significance to identify the mean difference between two quantitative variables. Scatter plots were used for graphical representation of data ( - Fig. 6). Pearson's correlation
Table 3 Institutional scoring system for cosmetic outcome assessment by independent observer

\begin{tabular}{|l|l|}
\hline No. & Score \\
\hline 1. & $\begin{array}{l}\text { 1. Absent } \\
\text { 2. Shallow } \\
\text { 3. Deep }\end{array}$ \\
\hline 2. & $\begin{array}{l}\text { 1. Poorly developed } \\
\text { 2. Well developed } \\
\text { 3. Excellent }\end{array}$ \\
\hline 3. & $\begin{array}{l}\text { 1. Perceptible } \\
\text { 2. Barely visible }\end{array}$ \\
\hline 4. & $\begin{array}{l}\text { 3. Imperceptible } \\
\text { 2. Present }\end{array}$ \\
\hline 3. Pbsent but stretched
\end{tabular}

was used to find the correlation between two quantitative variables. Correlation Coefficient of 0.6 to 1.0 was considered as strong positive correlation. $p$-Value of $<0.05$ was considered as statistically significant after assuming all the rules of statistical tests.

\section{Results}

All 42 transwomen (who had already undergone bottom surgery in an average period of 18 months before) had an average $3.75 \mathrm{~cm}$ of breast parenchyma palpated beyond the areolar border (with minimum of 2 years hormonal therapy) at the time of PAM. All had mild to moderate breast development with hormonal therapy. None had ptosis, tubular or contracted breast deformities. The average age was 32.62 years. The average BBD (measured at 


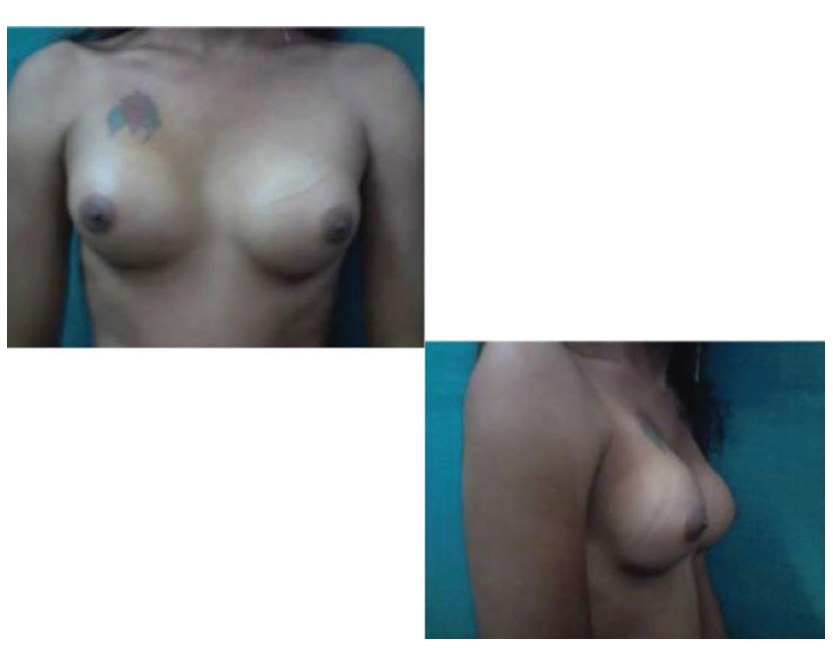

Fig. 3 Case 1 postoperative results at 36 months frontal and profile view.
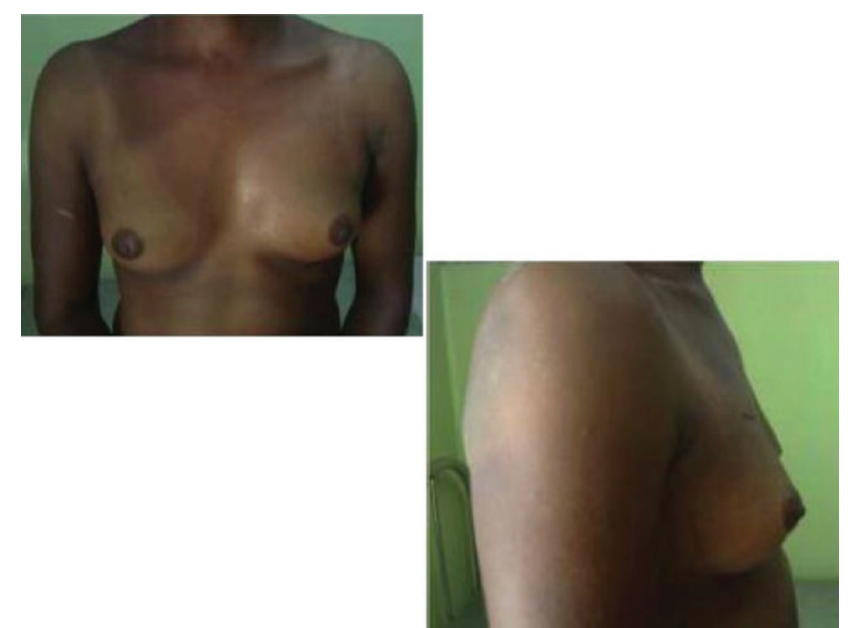

Fig. 4 Case 3 preoperative frontal and profile view.

nipple level from anterior axillary line to parasternal border) was $10.96 \mathrm{~cm}$. IMF incision was used in all cases. All patients had crisp IMF with imperceptible scar. Average base diameter of implant and volume of implant was $9.99 \mathrm{~cm}$ and $221.9 \mathrm{~mL}$, respectively. Round implant was used in 40 transwomen (95.2\%) and ACGI (4.8\%) was used in two transwomen. Forty-five percent of transwomen $(n=19)$ underwent dual plane breast pocket augmentation. All transwomen were followed for an average period of 45.14 months. Complications encountered in this series were migration of implant $(n=2 ; 4.8 \%)$ and piston effect $(n=1 ; 2.4 \%)$. These complications were noted only in the dual plane augmentation cases ( $\mathbf{- T a b l e} \mathbf{1}$ ).

\section{Results of Statistical Analysis}

Mean age of subjects was $32.62 \pm 3.68$ years, mean breast base diameter was $10.96 \pm 0.62$, mean base implant base diameter was $10.00 \pm 0.57$, mean volume of implant was

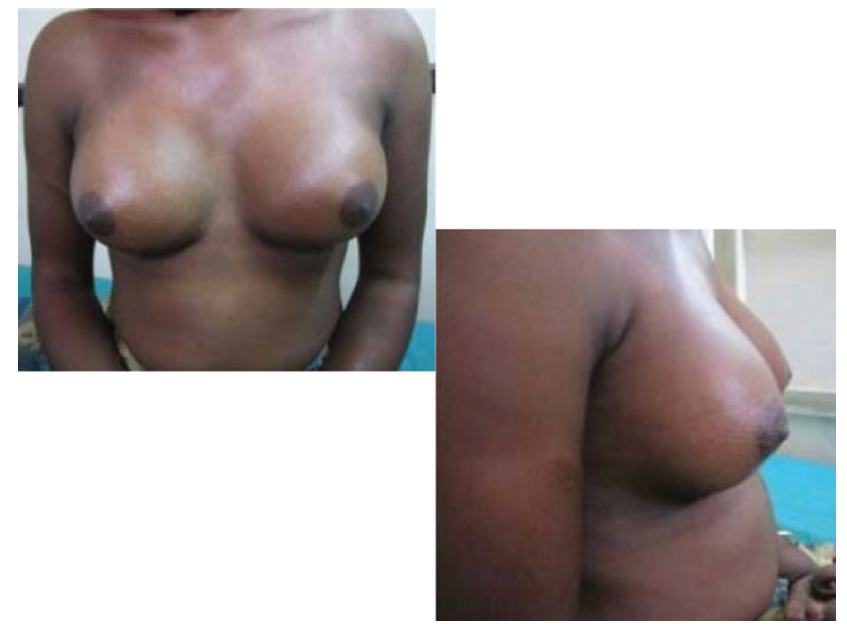

Fig. 5 Case 3 postoperative result at 40 months frontal and profile view.

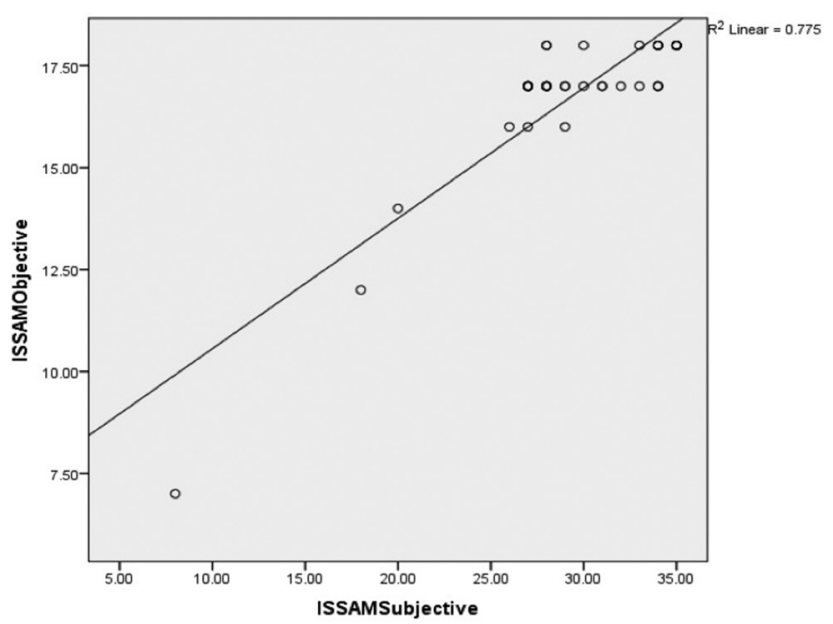

Fig. 6 Scatter plot showing correlation between ISSAM subjective scores and ISSAM objective score. ISSM, institutional score system for augmentation mammoplasty.

$221.90 \pm 55.71$, and mean duration of follow-up was $25.14 \pm 5.47$ months. A total of $90.5 \%$ was positive for retroviral status (-Table 4 ). In the study, $4.8 \%$ had anatomical cohesive gel implant and $95.2 \%$ had round implant. Also, $38.1 \%$ had high-profile, $23.8 \%$ had medium-profile, and $23.8 \%$ had low-profile implant. Again, $45.2 \%$ had dual plane (DP) augmentation and $54.8 \%$ had SG/SF plane implant (-Table 5). In the study, both ISSAM-S and -O showed grade A in $92.9 \%$, grade B in $4.8 \%$, and grade $C$ in $2.4 \%$ (-Table 6 ). In the study, there was significant positive correlation between ISSAM-S and ISSAM-O. that is, with increase in ISSAM-S score, there was increase in ISSAM-O score and vice versa (-Table 7 ; - Fig. 6 ). In the study, $92.9 \%$ had no complications, $4.8 \%$ had migration, and $2.4 \%$ had piston effect (-Table 8 ). In the study, significant association was observed between ISSAM-S and-O score as described by Chi-square test ( $p<0.001$; - Table 9).

All transwomen felt that their feminine feeling was reinforced and increased after surgery. 
Table 4 Profile of subjects in the study

\begin{tabular}{|l|l|l|l|l|l|}
\hline & $n$ & Mean & SD & Median & 95\% Cl \\
\hline Age (y) & 42 & 32.62 & 3.68 & 33.50 & $31.47-33.76$ \\
\hline Breast base diameter & 42 & 10.96 & 0.62 & 11.00 & $10.77-11.1$ \\
\hline Base implant base diameter & 42 & 10.00 & 0.57 & 10.00 & $9.99-9.81$ \\
\hline Volume of implant & 42 & 221.90 & 55.71 & 230.00 & $204.5-239.2$ \\
\hline Follow-up (mo) & 42 & 25.14 & 5.47 & 24.00 & $23.44-26.85$ \\
\hline
\end{tabular}

Abbreviations: $\mathrm{Cl}$, confidence interval; SD, standard deviation.

Table 5 Implant profile among study patients

\begin{tabular}{|l|l|l|l|}
\hline \multicolumn{2}{|l|}{ Shape of implant } & Count & $\%$ \\
\cline { 2 - 4 } & Anatomical cohesive gel implant & 2 & 4.8 \\
\cline { 2 - 4 } & Round implant & 40 & 95.2 \\
\hline \multirow{3}{*}{ Profile of implant } & High profile & 16 & 38.1 \\
\cline { 2 - 4 } & Medium profile & 16 & 38.1 \\
\cline { 2 - 4 } & Low profile & 10 & 23.8 \\
\hline \multirow{2}{*}{ Implant pocket } & Dual plane & 19 & 45.2 \\
\cline { 2 - 4 } & Subglandular/subfascial & 23 & 54.8 \\
\hline
\end{tabular}

Table 6 ISSAM-S and ISSAM-O grade distribution

\begin{tabular}{|l|l|l|l|l|}
\hline \multirow{2}{*}{} & \multicolumn{2}{|l|}{ ISSAM-S } & ISSAM-O & $\%$ \\
\cline { 2 - 5 } & Count & $\%$ & Count & 92.9 \\
\hline A & 39 & 92.9 & 39 & 4.8 \\
\hline B & 2 & 4.8 & 2 & 2.4 \\
\hline C & 1 & 2.4 & 1 & \\
\hline
\end{tabular}

Abbreviations: ISSAM-O, institutional score system for augmentation mammoplasty-objective; ISSAM-S, institutional score system for augmentation mammoplasty-subjective.

Table 7 Correlation between ISSAM-S and ISSAM-O scores

\begin{tabular}{|l|l|l|l|}
\hline \multicolumn{2}{|c|}{} & ISSAM-S & ISSAM-O \\
\hline \multirow{3}{*}{ ISSAM-S } & $r$ & 1 & $0.880^{\text {a }}$ \\
\cline { 2 - 4 } & $p$-Value & & $<0.001^{\text {b }}$ \\
\cline { 2 - 4 } & $N$ & 42 & 42 \\
\hline \multirow{2}{*}{ ISSAM-O } & $R$ & $0.880^{\text {a }}$ & 1 \\
\cline { 2 - 4 } & $p$-Value & $<0.001^{\text {b }}$ & 42 \\
\cline { 2 - 4 } & $n$ & 42 & \\
\hline
\end{tabular}

Abbreviations: ISSAM-O, institutional score system for augmentation mammoplasty-objective; ISSAM-S, institutional score system for augmentation mammoplasty-subjective.

${ }^{a}$ Correlation is significant at the 0.01 level (two-tailed).

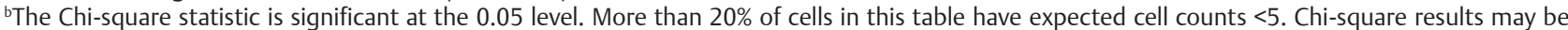
invalid.

Table 8 Complications distribution among patients

\begin{tabular}{|l|l|l|l|}
\hline \multicolumn{2}{|c|}{} & Count & $\%$ \\
\hline \multirow{3}{*}{ Complications } & Nil & 39 & 92.9 \\
\cline { 2 - 4 } & Migration & 2 & 4.8 \\
\cline { 2 - 4 } & Piston effect & 1 & 2.4 \\
\hline
\end{tabular}


Table 9 Association between ISSAM-S and ISSAM-O grades

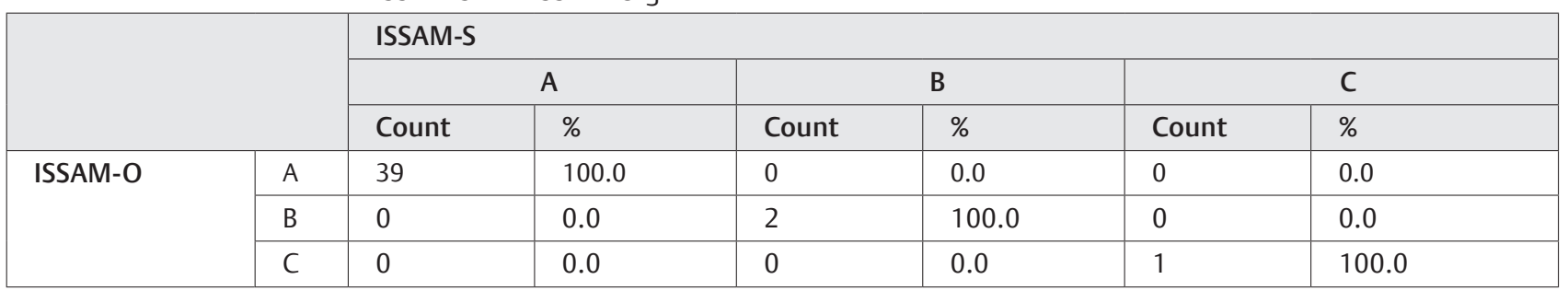

Abbreviations: ISSAM-O, institutional score system for augmentation mammoplasty-objective; ISSAM-S, institutional score system for augmentation mammoplasty-subjective.

\section{Discussion}

PAM in transwomen is not all about providing big breasts; rather it is about establishing the natural shape, feel and balancing it with the overall body contour, and at the same time minimizing the male chest stigmata and operated look. The aim of mammoplastic surgeon operating on the transwomen must be to obtain all these objectives with least or no complications. The preoperative consultation with patients according to the author must be elaborate to finalize the shape and size of the breast implant. Most common request by the transwomen is to have a large esthetic breast. So it is very important to finalize the shape and size of the implant taking into consideration the following factors: (1) configuration and measurements of the chest; (2) body habitus; (3) pectoral development; and (4) shape, size, and characters of existing breast in such a way that lasting results will be obtained. Despite the fact that the breast implants are readymade in various dimensions and styles, ${ }^{3-5}$ they can be rendered fit to each individual based on the close study of above factors. Heeding to consumers requests for larger volume implants, though may result in short-term pleasing effects, in author's opinion most of the time it can go in for complications like postoperative pain, reoperations due to atrophy, and malposition. Therefore a surgeon with full understanding of male chest tissue characters and a transwomen with full knowledge of large volume implant complications shall pave way for an esthetically lasting prosthetic augmentation mammoplasty. ${ }^{6}$ Transgender persons seek surgical interventions such as PAM to achieve the physical transformations that hormone therapy alone cannot produce. ${ }^{7-12}$ Author's protocol of minimum 2-year preoperative hormonal therapy results in mild-to-moderate breast growth in transwomen facilitating PAM with good stretchable envelope and well developed nipple and areola that culminates in good esthetic results. Author's opinion is mammogenesis in transwomen is not related to the dose of hormone but on the duration of therapy. Kanhai et $\mathrm{al}^{7}$ in their study stressed the need for hormonal therapy and concluded that insufficient breast development occurs in many and results in poor outcome. Another contributing factor in their study for poor outcome is most of them are adolescent age transwomen and therefore, the age related developments cannot keep up the growth in the inherent breast envelope. In the study, one of the contributing factors for the good esthetic results is the average age of the transwomen is 32.7 years that is well after the adolescent age related changes. Though the size of the study is small, it is reasonable to conclude that the well-developed breast envelope with minimum 2 years of hormonal therapy greatly facilitates the good outcome. As the ACGI demands wider access incision and are prone for easy malpositions (common in the transwomen who have more physical activity), it has been restricted only to the most suitable two cases in the author's study where the SNN distance exceeded $21 \mathrm{~cm}$. Only round silicone gel filled textured implants are used in other cases. For the best cosmetic outcomes, author recommends strict observation of the following factors: (1) learning the differences between male and female chest anatomy (wider chest and well-developed pectoralis major with fascia) and how to feminize the male chest without any stigmata; (2) minimum 2 years of preoperative hormonal therapy; (3) proper timing of surgery; (4) proper selection of implant; (5) appropriate surgical approach (proper preoperative marking, location of incision, and choice of plane of implant pocket); and (6) vision of the expected results, complications, and their implications on psychosocial outcomes. The final esthetic outcome of PAM in the transwomen is the resultant of dynamic interaction of breast parenchyma characteristics (quantity, stretchability, and consistency) with breast implant characteristics (plane in the chest wall, shape, and dimensions). ${ }^{13}$ According to author, the SF/SG implant position is the best for the textured round implant in transwomen for the following reasons: (1) in all cases during the dissection of this plane author finds that the pectoral deep fascia is well-developed; (2) textured implants make the wide adherence to this fascia firmly ${ }^{14,15}$ and paves way for the implant stabilization; (3) the tough fascia and texurity ${ }^{15}$ of the implant complement each other in decreasing the incidence of contracture and this is also as noted in our series; (4) through inframammary access this pocket is technically quick and easy to dissect and provides unparallel wide direct visualization that prevents injury to the cutaneous nerves (this has led to maintenance of sensation of NAC in our series and nil infection related complications); (5) when appropriately chosen (pinch fold thickness is greater than $2.5 \mathrm{~cm}$ ), this reduces the implant visibility and palpability; (6) animation disorders like "window shade deformity" and "piston effects" are not seen in this position; (7) since overlying breast tissue is not handled directly, it facilitates its normal development; and (8) postoperative comfort is greatly increased as seen in author series. Whenever patient has asthenic body habitus 
and pinch fold thickness less than the $2.5 \mathrm{~cm}$, the authors' preferred technique is subpectoral dual plane insertion. ${ }^{16}$ All these anatomy directed steps perceived by the author paves way for the best results in this series. It is authors' practice to give the inframammary access incision $0.5 \mathrm{~cm}$ below the proposed or existing inframammary fold as the postoperative stretching in the lower pole over the period of time and technique of layered closure brings crisp IMF with imperceptible scar. We have now enriched armamentarium of implants, thanks to the advancements in implant science leading to reproducible beautiful results and increased safety of the procedure. In coherent with the study by Weigert et al, ${ }^{6}$ all transwomen in the author's study felt that their feminine feeling is enhanced with PAM.

\section{Conclusion}

The hormonal therapy and surgery are the two promising portfolios for male-to-female transgenders to bank upon, to quench their innate pertinacious and indefatigable desire to align their body identity with their gender identity. PAM gives finishing and colossal touch to orient their somatic sex to psychic sex. To get the best cosmetic outcome and lasting results, the PAM in transwomen has to be made a more reasonable and scientific procedure rather than an emotional and irrational procedure. Author's anatomy based PAM approach facilitates transwomen to rejoice their genderness in harmony with their gender identity.

\section{Funding \\ None.}

\section{Conflict of Interest}

None declared.

\section{References}

1 Coleman E, Bockting W, Botzer M, et al. Standards of care for the health of transsexual, transgender, and gender-nonconforming people, version 7. Int J Transgenderism 2012;13(4):165-232

2 Thalaivirithan BM, Sethu M, Ramachandran DK, Kandasamy $\mathrm{M}$, Janardhanam J. Application of embryonic equivalents in male-to-female sex reassignment surgery. Indian J Plast Surg 2018;51(2):155-166
3 Cunningham B. The mentor study on contour profile gel silicone memorygel breast implants. Plast Reconstr Surg 2007;120(7, Suppl 1) :33S-39S

4 Maxwell GP, Van Natta BW, Murphy DK, Slicton A, Bengtson BP. Natrelle style 410 form-stable silicone breast implants: core study results at 6 years. Aesthet Surg J 2012;32(6):709-717

5 Stevens WG, Harrington J, Alizadeh K, et al. Five-year follow-up data from the U.S. clinical trial for Sientra's U.S. Food and Drug Administration-approved Silimed brand round and shaped implants with high-strength silicone gel. Plast Reconstr Surg 2012;130(5):973-981

6 Weigert R, Frison E, Sessiecq Q. Al Mutairi K, Casoli V. Patient satisfaction with breasts and psychosocial, sexual, and physical well-being after breast augmentation in male-to-female transsexuals. Plast Reconstr Surg 2013;132(6):1421-1429

7 Kanhai RC, Hage JJ, Karim RB, Mulder JW. Exceptional presenting conditions and outcome of augmentation mammaplasty in male-to-female transsexuals. Ann Plast Surg 1999;43(5):476-483

8 Hage JJ. Medical requirements and consequences of sex reassignment surgery. Med Sci Law 1995;35(1):17-24

9 Asscheman H, Gooren LJG. Hormone treatment in transsexuals. J Psychol Human Sex 1992;5:39-54

10 Kanhai RCJ, Hage JJ, Asscheman H, Mulder Jw. Augmentation mammoplasty in male to female transsexuals: basic considerations and review of literature. Plast Reconstr Surg 1973;51:628-631

11 Kanhai RC, Hage JJ, Mulder JW. Long-term outcome of augmentation mammaplasty in male-to-female transsexuals: a questionnaire survey of 107 patients. Br J Plast Surg 2000;53(3):209-211

12 Kanhai RC, Hage JJ, Karim RB. Augmentation mammaplasty in male-to-female trans-sexuals: facts and figures from Amsterdam. Scand J Plast Reconstr Surg Hand Surg 2001;35(2):203-206

13 Tebbetts JB. Dual plane breast augmentation: optimizing implant-soft-tissue relationships in a wide range of breast types. Plast Reconstr Surg 2001;107(5):1255-1272

14 Góes JCS, Landecker A. Optimizing outcomes in breast augmentation: seven years of experience with the subfascial plane. Aesthetic Plast Surg 2003;27(3):178-184

15 Graf R, Pace DT, Damasio RC, et al. Subfascial breast augmentation. In: Innovations in Plastic and Aesthetic Surgery. New York, NY: Springer; 2008 406-413

16 Claes KEY, D’Arpa S, Monstrey SJ. Chest surgery for transgender and gender nonconforming individuals. Clin Plast Surg 2018;45(3):369-380 